\title{
A comparative study of early and delayed cord clamping in term deliveries
}

\author{
Nikita V. Gonnade, Surendra D. Nikhate*, Himadri Bal, Nikita Shrivastava
} Department of Obstetrics and Gynecology, Dr. D. Y. Patil Medical College, Dr. D. Y. Patil Vidyapeeth, Pune,
Maharashtra, India

Received: 18 September 2018

Accepted: 22 October 2018

*Correspondence:

Dr. Surendra D. Nikhate

E-mail: hellosun2000@gmail.com

Copyright: (c) the author(s), publisher and licensee Medip Academy. This is an open-access article distributed under the terms of the Creative Commons Attribution Non-Commercial License, which permits unrestricted non-commercial use, distribution, and reproduction in any medium, provided the original work is properly cited.

\begin{abstract}
Background: Timing of clamping of the umbilical cord has always been a debatable issue. Early cord clamping (ECC) is defined as clamping of the cord within 30 seconds of delivery of the baby and delayed cord clamping (DCC) is defined as clamping of the cord between 30 to 120 seconds of delivery. Delayed cord clamping, despite some limitations, is said to be beneficial to the neonate. A comparative study between ECC and DCC was carried out on a select group of term pregnant women without any high-risk factor and delivering at term. Aim of the study was to compare the effects of early versus delayed cord clamping on neonates and mothers. The focus was on the neonatal haemoglobin levels and adverse effects, if any on neonates and mothers in the two groups.

Methods: 100 women satisfying the inclusion/exclusion criteria were recruited for the study. They were randomly divided into two groups of 50 each. Group A underwent early cord clamping and Group B delayed cord clamping. Mothers were observed for 1 hour post-delivery for any evidence of post-partum haemorrhage. Neonates were observed for any sign of tachypnea and blood sample was sent after 72 hours of delivery for analyzing Hb, hematocrit and bilirubin of the neonate.

Results: The results revealed that neonates with DCC had a higher mean Hb level of 15.02 vis-à-vis the ECC group $\mathrm{Hb}$ of $11.69 \mathrm{G} / \mathrm{dl}$ and the difference was statistically significant. Similarly mean hematocrit of DCC group was 48.67 while the ECC group mean was 42.36 , the difference again was statistically significant. There was no significant side effects or complications in both mother and newborn babies.

Conclusions: It was concluded that delayed cord clamping should be practiced in otherwise non high-risk deliveries.
\end{abstract}

Keywords: Early cord clamping, Delayed cord clamping, Neonatal bilirubin levels, Neonatal hematocrit levels

\section{INTRODUCTION}

The umbilical cord since time immemorial has fascinated physicians. Hippocrates and Galen postulated its role in foetal nutrition and Trotula provided specific instructions for cord cutting. ${ }^{1}$

He said it should be tied, a charm spoken during the cutting, and then wrapped with the string of an instrument that is plucked or bowed. Nevertheless, no mention of timing was made. Cord cutting is necessary for the separation of the neonate from the placenta. Inch described the practice in primitive cultures. He mentioned that the cord is not cut until the delivery of the placenta, even hours later. It is unclear when this practice changed. ${ }^{2}$

The practice of early cord clamping began in $17^{\text {th }}$ century with the appearance of male midwives who preferred women giving birth in bed, thus interfering with the physiologic process of third stage which required more frequent manual removal of the placenta. So, early 
clamping likely originated as a procedure for the needs of the provider. If you are going to do manual removal of placenta having the cord clamped and cut makes it much easier. While cutting of the cord is a necessity, the basis behind clamping is more controversial. In 1968, Botha examined the early literature on cord clamping, from 1668 onwards. $^{3}$

The neonatal clamp was initially employed to avoid blood loss from the baby before physiological closure of the umbilical vessels. Timing of cord clamping remains a disputable issue. Traditionally early cord clamping (ECC) was done and baby was handed over to the attending paediatrician, resident or nurse. However, in recent times the concept of delayed cord clamping is being stressed upon almost in all cases. Delayed cord clamping (DCC), is defined as clamping of the umbilical cord between 30 and 120 seconds after birth or when cord pulsations stops. Delayed cord clamping has been associated with increased placenta-to-neonate transfusion leading to an increase in neonatal blood volume at birth. It is said that this increases iron stores and decreases the risk of anemia.

Again, other studies suggest that delayed cord clamping may have adverse neonatal effects with increased risk of respiratory symptoms, polycythaemia, hyperbilirubinaemia and thereby need for phototherapy. ${ }^{4}$ Possible advantages of early cord clamping include permitting prompt resuscitation and treatment of the newborn, harvesting of stem cells for public blood banking and prevention of potential postpartum haemorrhage, although the latter is not viewed as an advantage in some guidelines. ${ }^{5}$ This clinical study was undertaken to compare the effects of delayed versus early cord clamping on the neonate and the mother in the postpartum period.

\section{METHODS}

This prospective observational study was carried out on pregnant women in labour at term in a tertiary care teaching hospital between September 2014 and August 2016. Institutional ethical committee clearance was obtained.

\section{Inclusion criteria}

- Term pregnant women without any high-risk factor and having foetus with vertex presentation undergoing vaginal or abdominal delivery.

\section{Exclusion criteria}

- Gestational hypertension, diabetes, heart disease, anaemia

- IUGR/severe oligohydramnios, polyhydramnios, congenital malformation, Rh incompatibility, multiple pregnancy, acute foetal distress.

- $\quad$ APH, PROM, abnormal presentation, traumatic PPH.

The study population comprised of 100 pregnant women at term as per the inclusion/exclusion criteria undergoing delivery in our hospital. Written informed consent was taken from all the selected cases. Detailed history taking, and examination was done. The patients were divided randomly into two groups of 50 each of ECC and DCC by a chit system. A bowl containing 100 chits of equal number of ECC and DCC was taken. Patient was asked to pick up the chit from the bowl and ECC or DCC was done as per the chit.

Deliveries were managed as per the institutional protocol. Group A (early cord clamping) had patients where cord clamping was done within 30 seconds and in Group B (delayed cord clamping) cord was clamped after 60 seconds. Inj oxytocin $10 \mathrm{mg}$ was used as prophylactic uterotonic for all patients at the time of delivery. Patients showing evidence of acute intrapartum fetal distress were excluded. Immediate neonatal resuscitation was carried out and babies were roomed in with mother. Any baby admitted to NICU after delivery (other than for short period of observation) was excluded from the study except those developing transient tachypnea of new-born.

Mothers were observed for 1 hour after delivery for evidence of atonic PPH ( $\geq 500 \mathrm{ml}$ for vaginal delivery and $\geq 1000 \mathrm{ml}$ for caesarean delivery). 72 hours after delivery neonatal blood for haemoglobin, haematocrit and serum bilirubin estimation was sent. The mothers and the newborns were evaluated with reference to neonatal haemoglobin, haematocrit and neonatal or maternal complications if any. Data was entered in excel sheet, the results were tabulated and statistically analysed by statistical package SPSS17.

\section{RESULTS}

The average age of women in group A and group B were 23.88 and 23.58 years and gestational age 38.98 and 38.84 weeks respectively and hence were comparable (Table 1).

Table 1: Comparison of Age and Period of gestation in group A and group B.

\begin{tabular}{|c|c|c|c|c|c|c|}
\hline \multirow[b]{2}{*}{ Parameter } & \multicolumn{2}{|c|}{ Group A $(\mathrm{n}=50)$} & \multicolumn{2}{|c|}{ Group B $(n=50)$} & \multirow{2}{*}{$\mathrm{Z}$ value } & \multirow[b]{2}{*}{ P value } \\
\hline & Mean & SD & Mean & SD & & \\
\hline Age (years) & 23.88 & 3.22 & 23.58 & 3.14 & 0.47 & 0.64 \\
\hline Period of gestation (weeks) & 38.98 & 1.06 & 38.84 & 0.84 & 0.73 & 0.47 \\
\hline
\end{tabular}


The groups were also matched for parity and mode of delivery and no significant difference was found (Table 2 and 3 respectively).

Table2: Parity wise distribution of cases in group A and group $B$.

\begin{tabular}{|llll|}
\hline Parity & Group A $(\%)$ & Group B $(\%)$ & Total \\
\hline Primigravida & $30(60)$ & $29(58)$ & 59 \\
\hline Multigravida & $20(40)$ & $21(42)$ & 41 \\
\hline Total & 50 & 50 & 100 \\
\hline
\end{tabular}

The birth weight in DCC group ranged between $2 \mathrm{~kg}$ to $3.6 \mathrm{~kg}$ with an average of $2.78 \mathrm{~kg}$. This was slightly higher in comparison to ECC group where the average was $2.64 \mathrm{Kg}$ (1.8 to $3.4 \mathrm{~kg})$.

Table 3: Mode of delivery wise distribution of cases in group $\mathbf{A}$ and group $\mathbf{B}$.

\begin{tabular}{|llll|}
$\begin{array}{l}\text { Mode of } \\
\text { delivery }\end{array}$ & Group A $(\%)$ & Group B $(\%)$ & Total \\
\hline Vaginal & $38(76)$ & $29(58)$ & 67 \\
\hline Caesarean & $12(24)$ & $21(42)$ & 33 \\
\hline Total & 50 & 50 & 100 \\
\hline
\end{tabular}

Chi-square $=3.66$, Degree of Freedom $=1, p=0.056$

Since birth weight was measured after the intervention, this was regarded as outcome variable (Table 4).

Table 4: Comparison of weight of baby in group A and group B.

\begin{tabular}{|c|c|c|c|c|c|c|}
\hline \multirow{2}{*}{ Parameter } & \multicolumn{2}{|c|}{ Group A (n=50) } & \multicolumn{2}{|c|}{ Group B (n=50) } & \multirow{2}{*}{$\mathrm{Z}$ value } & \multirow{2}{*}{ p value } \\
\hline & Mean & SD & Mean & SD & & \\
\hline Weight (Kg) & 2.64 & 0.37 & 2.78 & 0.32 & 2.01 & 0.047 \\
\hline
\end{tabular}

The difference, however, was not statistically significant. The range of haemoglobin in the ECC group babies was between 8 and $15 \mathrm{gm} / \mathrm{dl}$ with the mean of $11.69 \mathrm{gm} / \mathrm{dl}$. The DCC group range was $11.9-19 \mathrm{gm} / \mathrm{dl}$ with the mean of $15.02 \mathrm{gm} / \mathrm{dl}$. This difference was statistically significant ( $\mathrm{p}$ value $<0.0001$ ). Similarly, the mean haematocrit level was significantly higher in the DCC group with the mean of 48.67 (range 32-71\%) in comparison to the ECC group with the mean of 42.36 (range $30-70 \%$ ). p value 0.002 (Table 5).

Table 5: Comparison of haemoglobin and haematocrit levels in group A and group B.

\begin{tabular}{|lllllll|}
\hline \multirow{2}{*}{ Parameter } & Group A $(\mathbf{n}=50)$ & \multicolumn{2}{c}{ Group B $(\mathbf{n}=50)$} & Z value & p value \\
\hline $\mathrm{Hb}(\mathrm{gm} / \mathrm{dl})$ & Mean & SD & Mean & SD & 10.02 & $<0.0001$ \\
\hline Haematocrit level & 11.69 & 1.54 & 15.02 & 1.78 & 3.13 & 0.002 \\
\hline
\end{tabular}

Table 6: Comparison of serum bilirubin level in group A and group B.

\begin{tabular}{|c|c|c|c|c|c|c|}
\hline \multirow{2}{*}{ Sr. Bilirubin level } & \multicolumn{2}{|c|}{ Group A $(\mathrm{n}=50)$} & \multicolumn{2}{|c|}{ Group B $(n=50)$} & \multirow{2}{*}{$\mathrm{Z}$ value } & \multirow{2}{*}{ p value } \\
\hline & Mean & SD & Mean & SD & & \\
\hline Total (mg/dl) & 2.06 & 0.53 & 4.92 & 6.64 & 3.04 & 0.003 \\
\hline Direct (mg/dl) & 0.56 & 0.23 & 0.48 & 0.23 & 1.72 & 0.089 \\
\hline
\end{tabular}

Table 7: Post-Partum haemorrhage (PPH) wise distribution of cases in group $A$ and group $B$.

\begin{tabular}{lllll} 
Parameter & $\begin{array}{l}\text { Group A } \\
(\mathrm{n}=50)\end{array}$ & $\begin{array}{l}\text { Group B } \\
(\mathrm{n}=50)\end{array}$ & $\begin{array}{l}\mathrm{Z} \\
\text { value }\end{array}$ & $\begin{array}{l}\mathrm{p} \\
\text { value }\end{array}$ \\
$\mathrm{PPH}$ & $1(2 \%)$ & $2(4 \%)$ & 0.59 & $>0.05$ \\
\hline
\end{tabular}

The mean total bilirubin level of new-borns in group A was $2.06 \mathrm{mg} / \mathrm{dl}$ and in group B it was $4.92 \mathrm{mg} / \mathrm{dl}$ (Table 6) making the difference statistically significant ( $p$ value
0.003). There were no cases of transient tachypnea in either group. There were two cases of postpartum haemorrhage in group B (4\%) and 1 in group A $(2 \%)$ and difference was not significant (Table 7).

\section{DISCUSSION}

This study was aimed at comparing the effects of delayed and early cord clamping on certain neonatal and maternal parameters. Despite innumerable studies, questions still 
remain unanswered regarding the optimal way of managing birth. The optimal time-point for umbilical cord clamping after delivery has been under debate for several decades. Through this study we endeavoured to look into and compare both the beneficial and adverse effects of delayed and early cord clamping. The main disadvantages of DCC in newborns, which have been highlighted, are associated with events occurring close to birth. These are respiratory distress, polycythaemia, hyperbilirubinaemia and need for phototherapy. ECC in obstetric practice has been hypothesized to decrease maternal postpartum haemorrhage.

As per 2015 RCOG guidelines on clamping of umbilical cord, early clamping is within 30 seconds and delayed cord clamping is 60 seconds after birth for a healthy term newborn. ${ }^{6}$ In present study we also followed the RCOG guideline and delayed cord clamping was done 60 seconds after birth. In the present study the two groups of ECC and DCC were matched for their profiles of maternal age, period of gestation, and mode of delivery.

According to WHO guidelines 2014, delayed cord clamping allows physiological transition of placental blood to neonate, thereby increasing the total blood volume and level of haemoglobin. ${ }^{7}$ Studies have shown that delayed cord clamping after 60 seconds in term pregnancy provides $11 \%$ increase in total blood volume and $23 \%$ increase in erythrocyte volume. ${ }^{8}$

In present study we observed statistically significant increase in haemoglobin level in delayed cord clamping group (mean of $15.02 \mathrm{gm} / \mathrm{dl}$ ) in comparison to the early cord clamping group $(11.69 \mathrm{gm} / \mathrm{dl})$. In Cochrane database systemic review in 2008 on effects of cord clamping by McDonald, Middleton P, Dowswell T et.al., the hemoglobin levels measured at 24 and 48 hours of life were found significantly high in the group of babies subjected to delayed cord clamping than group of babies subjected to early clamping. ${ }^{9}$ The normal value of haematocrit in newborn till one month is in the range of 42-65\%. In present study mean haematocrit in ECC group was 42.36 whereas in DCC was 48.67, showing statistically significant difference.

There has been a concern of polycythaemia and hyperbilirubinaemia with DCC. Polycythemia is defined as Hct level $>65 \%$ and occurs in about $2 \%$ to $5 \%$ of term newborns. The primary concern with polycythemia is related to the development of blood hyperviscosity. Ricon D, Fouguet A et al found significant increase of polycythemia related clinical features in a number of newborns delivered with delayed cord clamping. Out of the 50 cases of DCC we found 6 cases $(12 \%)$ of polycythaemia with haematocrit $>65 \%$, but none of them required any active management

The risk of developing hyperbilirubinemia is another issue of concern in delayed cord clamping. Hyperbilirubinemia is associated with increase in red cell volume and/or with polycythaemia. Again, according to Ricon D, Fouguet A et.al. significant increase of hyperbilirubinemia was observed after delayed cord clamping. ${ }^{10}$ Rabe H, Diaz-Rossello et.al. found that none of the neonates with elevated bilirubin levels required phototherapy treatment or exchange transfusions. ${ }^{11}$ The normal range of total bilirubin in newborn is $<5 \mathrm{mg} / \mathrm{dl}$. In present study the mean total bilirubin level was 2.06 in ECC group and mean of 4.92 in DCC group.

Transient tachypnea of the newborn may occur as a result of delayed absorption of lung fluid caused by an increase in blood volume related to delayed cord clamping. Cernadas J, Carroli G, Pellegrini L et al found a slight increase in respiratory rate in those neonates who had delayed cord clamping at birth, however they required no additional respiratory therapy. ${ }^{12}$ A study carried out by Ersdal HL, Linde J. for the onset of spontaneous respiration in the newborn, found that delay in cord clamping resulted in $20 \%$ decrease in admission to neonatal intensive care unit and related morbidity. ${ }^{13}$ They concluded that the cord should not be clamped before the start of spontaneous respiration by the neonate.

In present study, we observed newborns for signs of respiratory distress up to 72 hours after birth and did not find any case of transient tachypnea. Data on obstetric complications, such as $\mathrm{PPH}$, were not consistently reported in earlier cord clamping trials. In the past it was postulated that DCC was a cause of PPH. However, literature does not show any significant evidence of increased incidence of PPH in DCC cases. In present study we found 2 cases of PPH in the delayed cord clamping group and one in the early clamping group, which were managed conservatively as per protocol.

The Cochrane review on this topic by McDonald, Middleton, Dowswell and Morris published in July 2013 came up with a significant conclusion. They reviewed 15 randomised trials involving 3911 women with their infants and found no significant difference in rates of postpartum haemorrhage in early and delayed cord clamping cases. However delayed cord clamping offered significant advantages to the infant in the form of increased birthweight, early haemoglobin concentration and raised iron stores upto 6 months of age. There is only a small risk in this group of neonatal jaundice requiring phototherapy as per the review. ${ }^{14}$

\section{CONCLUSION}

It was found that delayed cord clamping does have a beneficial effect on haemoglobin and haematocrit status of new-born. Hence it is felt that DCC will prevent iron deficiency and promote proper neurological development of the neonate. The side effects of delayed cord clamping are not significant. Therefore, delayed cord clamping should be the norm rather than an exception in term uncomplicated deliveries. 
Funding: No funding sources

Conflict of interest: None declared

Ethical approval: The study was approved by the Institutional Ethics Committee

\section{REFERENCES}

1. Green MH Trotula: an English translation of the medieval compendium of women's medicine. University of Pennsylvania Press, 2002

2. Inch. S. Management of the third stage of labour - A cascade of intervention. Midwifery. 1985;1(2):11422.

3. Botha MC. The management of umbilical cord in labour. S Afr J Obstetrics and Gynaecology. 1986;6:30-3.

4. Yao AC, Lind J, Vuorenkoski V. Expiratory grunting in the late clamped normal neonate. Pediat. 1971; 48(6):865-70.

5. Leduc D, Senikas V, Lalonde AB, Ballerman C, Biringer A, Delaney M, et.al. Active management of the third stage of labour: prevention and treatment of postpartum hemorrhage. SOGC Clinical Practice Guideline no. 235, October 2009. J Obstet Gynaecol Can. 2009;31(10):980-93.

6. RCOG release: Timing of clamping the umbilical cord analyzed in new opinion paper, 27 February 2015.

7. WHO. Guideline: Delayed umbilical cord clamping for improved maternal and infant health and nutrition outcomes. Geneva: World Health Organization. 2014.

8. Kluckow M, Hooper SB. Using physiology to guide time to cord clamping. Seminars in Fetal \& Neonatal. Med. 2015;20(4):225-231.
9. McDonald SJ, Middleton P, Dowswell T, Morris PS. Effect of timing of umbilical cord clamping of term infants on maternal and neonatal outcomes. Cochrane Database of Systematic Reviews. 2008;2: 40747.

10. Rincon D, Foguet A, Rojas M, Segarra E, Sacristan E, Teixidor R, et.al. Time of cord clamping and neonatal complications a prospective study. An Pediatr (Barc). 2014;81(3):142-8.

11. Rabe H, Reynolds G, Diaz-Rossello J. Early versus delayed umbilical cord clamping or cord milking for preterm babies (review). Cochrane Database Syst Rev. 2004(4):CD003248.

12. Cernadas J, Carroli G, Pellegrini L, Otano L, Ferrira M, Ricci C, Giordano D, Lardizabal J. The effect of cord clamping on neonatal venous haematocrit values and clinical outcome at term: A randomized controlled trial. Paediat. 2006;117(4):779-86.

13. Ersdal HL, Linde J, Mduma E, Auestad B, Perlman J. Neonatal outcome following cord clamping after onset of spontaneous respiration. Pediatrics. 2014; 134(2):265-272.

14. McDonald SJ, Middleton P, Dowswell T, Morris PS. Effect of timing of umbilical cord clamping of term infants on maternal and neonatal outcomes. Evidence-Based Child Health: A Cochrane Review J. 2014;9(2):303-97.

Cite this article as: Gonnade NV, Nikhate SD, Bal $\mathrm{H}$, Shrivastava N. A comparative study of early and delayed cord clamping in term deliveries. Int J Reprod Contracept Obstet Gynecol 2018;7:4929-33. 